\title{
Cultural planning practices in local government in Victoria
}

\author{
Kim Dunphy ${ }^{\mathrm{a}}$, Lyndall Metzke ${ }^{\mathrm{b}}$ and Linda Tavelli ${ }^{\mathrm{c}}$ \\ a Cultural Development Network, Australia, \\ kim.dunphy@culturaldevelopment.net.au \\ b Cultural Development Network, Australia, lyndall@culturaldevelopment.net.au \\ ${ }^{\mathrm{c}}$ Department of Culture and the Arts, Western Australia, \\ linda.tavelli@dca.wa.gov.au
}

\begin{abstract}
Cultural development is a relatively new area of focus in local government, with local government areas increasingly employing staff within dedicated areas of council over the last 20 years. Practices tend to vary significantly between councils, because there is as yet no specific training nor agreed professional standards for cultural development. This paper presents results of a state-wide survey about cultural planning practices in local government across Victoria, reporting on breadth of cultural planning, amount of investment, policy influences in their development and planning processes. Findings indicate that all Victorian councils provide some kind of cultural development activity, with all but the smallest shires making considerable investment in staff, venues, programming and support for local initiatives. Cultural plans are increasingly being implemented, with more than $75 \%$ of councils having a published plan or one in progress. Scope for practice improvement was also evident, with few plans indicating any use of data, evidence or measurement strategies. In offering this picture of the current state of professional activity of cultural development in local government in Victoria, this research offers the potential for stronger practice, improved collaboration and increasingly shared standards between councils.
\end{abstract}

\section{Introduction}

The expansion of local government responsibility over recent decades beyond the traditional roads, rates and rubbish remit has led to new areas of work becoming a stronger focus. Council amalgamations across much of Australia have resulted in larger organisations offering increasingly sophisticated services by staff with specialised skills. These two factors have contributed to a growing investment in cultural development in local government in 
Australia, with LGAs increasingly employing cultural development staff within dedicated areas of council over the last 20 years.

Because there is as yet no specific standard training nor agreed professional standards for this area, practices tend to vary significantly between councils. Councils make significant investment in cultural development, but as yet, there has been little formal research on what they do or how they do it. Individual councils must undertake their own enquiry any time they seek to compare or contrast their own practice with others. This indicates significant potential for research that can help inform councils on topics related to cultural development.

This paper presents results of a state-wide survey about cultural planning practices in local government across Victoria. It opens with a literature review on cultural development planning practices around the world and current investment in cultural development in Australian and Victorian councils. Topics addressed through this research include the amount and distribution of investment of staff and resources in cultural development, how cultural development is aligned with other areas of local government endeavor, principles that inform the development of cultural plans and strategies for measurement of outcomes.

\section{Literature review}

\section{Culture as a dimension of local government policy and practice}

Local government entities around the world are increasingly considering culture, as the fourth dimension of public policy, as part of their remit along with social, economic and environmental considerations. This change is being promulgated by the Commission for Culture of the international peak body for local government, United Cities and Local Governments (UCLG). The concept of culture as a domain of human activity that should be recognized in public policy has been formally recognised since at least 1982, when the World Conference on Cultural Policies in Mexico City developed a series of principles to govern cultural policy. This conference came to a definition of culture as 'the whole complex of distinctive spiritual, material, intellectual and emotional features that characterize a society or social group. It includes not only arts and letters, but also modes of life, the fundamental rights of the human being, value systems, traditions and beliefs' (UNESCO, 1982). This rhetoric developed up until the turn of the century, culminating in the UNESCO Universal Declaration on Cultural Diversity in November 2001.

The idea of culture as a fourth pillar of sustainability was formalised by Hawkes in 2001, in a monograph focused on the local government context (Hawkes 2001). This idea has since 
been adopted by local governments internationally, with more than 200 cities now signatories to UCLG's Agenda 21 for Culture, which promotes the four pillars as a fundamental principle (Agenda 21 for Culture 2012). Between 2002 and 2012, New Zealand adopted culture as one of the four dimensions of well-being that local government must report against (Dalziel, Matunga \& Saunders 2006).

Blomkamp (2011) observes that the local level of cultural policy is increasingly being recognised as important by scholars, politicians and practitioners (Craik 1997; UCLG 2004; Murray 2005; Choudharey 2009). She documents recent trends in cultural planning, especially in Australia (Mills 2003; Stevenson 2010), and international research that shows that the 'most well-developed and practical' policy initiatives with participatory strategies are at the local level (Murray 2005, p. 48).

However, this focus on culture is not yet a legislative requirement for local government in Victoria. The Local Government Act only requires local councils to report on social, economic and environmental dimensions of their activity (Local Government Act 1989). The Essential Services review undertaken by the State Government in 2010 determined that, as activity was so different in each LGA, there was no possibility of positing a regulation structure for planning or service provision of cultural development (Dunphy 2010).

Nevertheless, most councils in Victoria have a range of cultural development activities, varying significantly depending on their size and resources. These include dedicated staff; venues, including libraries, museums and community halls; public art; festivals; heritage; and grants to artists and community groups (Dunphy 2006; Blomkamp 2011). The independent non-profit association Cultural Development Network has been working to support this sector since 2000, and the Municipal Association of Victoria (state peak body) and LG Pro (local government professional network) both established their first Arts and Culture Committee in 2012 in response to the growing engagement of local government in this area.

\section{Challenges with terminology}

One of the challenges in the field relates to terminology. The term culture is typically used interchangeably with the arts, such that local government departments are often entitled 'Arts and Culture', when their focus is specifically arts. This practice parallels that in other areas of public policy and scholarship. For example, Meyrick's article that promises, beguilingly 'to explain culture ... the relationship between the idea of culture and the different ways it is talked about in the contemporary world' (2013, p. 1), in fact offers no 
explanation of the concept of culture beyond its appropriation as a synonym for the arts. Yue, Khan and Brook's (2011) research project about cultural indicators in a local government context provides an unusual exception. In their proposed framework, these authors consider culture in relation to the arts, as well as in an anthropological sense, in relation to multi-cultural policy and diversity.

In this article, the term 'cultural development' will be applied as per its most common usage, to refer to arts services or policies offered or supported by council. These are presumed to address the function of local government 'to improve the overall quality of life of people in the local community' (Local Government Act 1989, p. 20), or, as UCLG's Agenda 21 advocates, 'to work towards a healthy, safe, tolerant and creative society (rather than merely a financially prosperous one)' (2010, p. 5).

The many other functions of councils that also have a relationship to culture, including diversity services and planning, education, indigenous issues and youth, will not be discussed. Nor does this article report on the issue that Hawkes was advocating in his Fourth Pillar of Sustainability (2001), the integration of a cultural dimension within all areas of council activity and reporting.

\section{Research about cultural development in local government in Australia}

Cultural development planning practices in local government in Australia are an underdocumented area of professional activity. This mirrors the situation elsewhere in the world. The Australian Centre for Excellence in Local Government resource library, for example, until recently did not include any references on the theme of culture or the arts. A small number of researchers have been examining aspects of cultural development in local government, particularly related to councils' uses of indicators to measure activity in the areas of culture and the arts (for example, Badham 2009; Blomkamp 2011; Blomkamp 2012; Dunphy 2010; Dunphy 2012; Yue, Khan \& Brooks 2011). Yue, Khan and Brooks (2011) comment on the value of cultural planning for local government because of its contribution to diversity, revitalisation of place, and generation of productivity.

To our knowledge, no research process has been undertaken that comprehensively examines cultural development planning practices in local government in Australia. However, Blomkamp offers a preliminary analysis of cultural plans and accountability documents from a small number of urban councils (Blomkamp 2011). She observes policy that addresses the broader cultural dimension beyond the arts, including cultural development, indigenous and multicultural/ diversity issues. Within cultural development 
policies, she identifies five categories of themes, emphasised to varying degrees in different councils. These are: political discourses of rights and citizenship; economic discourses of creative industries and cultural tourism; social concepts related to identity, health, social capital, and quality of life; the environmental paradigm of sustainable development; and cultural themes such as vitality, diversity, heritage, education, and artistic or aesthetic values (Blomkamp 2011, p. 5). These roughly correspond to the four pillars of social, economic, environmental and cultural sustainability identified by Hawkes (2001), with the addition of the political dimension that Blomkamp distinguishes from the social.

\section{Evidence based planning and decision-making}

This lack of research and data in the cultural development sector is occurring in a context in which councils are increasingly expected to undertake evidence based planning and decision-making. While not all Australian states require their local authorities to undertake strategic planning, most councils do apply it in practice (Local Futures 2006, p. 47). In their planning approaches, organisations are being encouraged to consider 'the broader changes in attitudes, behaviour or perceived well-being as a result of the intervention in question' (Johnston \& Memon 2008, p. 16). A stronger focus is being made on outcomes, rather than the means to those ends. As researchers from the Community Indicators Victoria advise: 'The tool used to deliver improvement - whether services, programs, capital projects, advocacy, grant funding etc. - is far less relevant than the outcome, or real difference, experienced by the community' (West \& Cox 2009).

This is a departure from earlier planning approaches which were much more concerned with inputs and outputs. Consequently, councils more than ever require data to inform their planning and policy indicators to help evaluate, measure and legitimise the impact of their work (Blomkamp 2011; Poirier 2005; Johnston \& Memon 2008).

Researchers frequently call for more critical analysis of concepts and indicators in policy frameworks (Blomkamp 2011; Mercer 2002; Badham 2009; Choudharey 2009). A common criticism is that norms and goals are not explicitly stated (Darlow 1996; Dunphy 2010; Markusen \& Gadwa 2010; O’Shea 2012). This makes measurements of progress difficult to establish and reduces the evaluability of cultural planning initiatives (Evans 2005).

Blomkamp observes this lack of use of strategic plans and measurement frameworks in arts and culture departments in Australian councils (Blomkamp 2011). She provides a case study of the cultural development department of a major Australian city, where the focus is primarily on service delivery, with an operational model of inputs (funding) and outputs 
(grants and productions). Despite rhetoric about results-based evaluation and accountability in this council, the reality in practice is that outcome evaluation is not yet well established and systematic use of results based indicators or SMART (specific, measurable, achievable, realistic, timely) principles has not yet occurred (Blomkamp 2012).

One of the barriers to evidence-based planning and decision-making is a lack of relevant and available data. Ley argues for the development of a local government-specific research discipline to address this challenge (Ley 2013). The benefits he anticipates of such a development include improved understanding of local areas and communities; more informed debate about issues, policies and decisions; more effective service; and better accountability and monitoring of progress (2013, p. 9).

In an article from the USA that identifies the lack of evidence-based decision-making in local government cultural development practice, Markusen and Gadwa (2010) suggest four areas of inquiry. Firstly, they advise researchers to evaluate cultural planning outcomes according to implicit and explicit norms and goals. Second, they recommend challenging the most frequently employed rationale for cultural initiatives - the theorised causal link to economic development. Then, they suggest going beyond development of metrics to gauge whether or not a cultural plan has generated anticipated outcomes, to also examining process and its influence on product. And finally, they suggest that the merits and weaknesses of specific alternative cultural strategies be examined (p. 388).

Having introduced the context of a growing focus on culture in public policy, the move toward evidence-based policy making, and challenges with local policy development, this article now presents data collected about cultural planning processes in Victoria. This provides a picture of current practice to inform councils and related bodies, and provide impetus for further research and improvements in practice.

\section{Method}

The research for this paper was undertaken in two stages. Internet searches of councils' websites in September 2012 and May 2013 provided the first set of data on published information about cultural plans. Information that could not be found online was sought through phone interviews with staff from the cultural development sections of LGAs across Victoria in May 2013. 


\section{Findings}

\section{Investment in local government cultural development activity in Australia}

This recognition of culture and cultural development in local policy is reflected in increasing investment in activity. In 2010-11, local government appropriated 19\% (\$1,259.9 $\mathrm{m}$ ) of the estimated total government expenditure on cultural activities (ABS 2012). These expenditure levels generally reflect the size of the population, with highly populated states spending more. In Victoria that year, local government authorities spent an estimated \$354.8 million on cultural activities. The largest spending local government in Victoria, the City of Melbourne, had \$14 million in its arts budget for 2013-2014, up from \$12.8 million in 20122013. Other councils' allocations to cultural development include $\$ 2,069,000$ for 'Arts, Culture and Venues' in a large inner-metro council to \$144,147 for 'Arts and Culture' in a small regional shire.

Average local government cultural expenditure across the nation in 2010-11 was $\$ 56.80$ per capita, up 4\% from 2009-10. South Australia had the highest per capita expenditure at $\$ 67.00$, followed by Victoria with $\$ 64.60$ and New South Wales with $\$ 57.10$. In Victoria, this was an increase of $10 \%$ from the year before, and more than 30\% increase since 2000-1 when per capita expenditure was $\$ 50$.

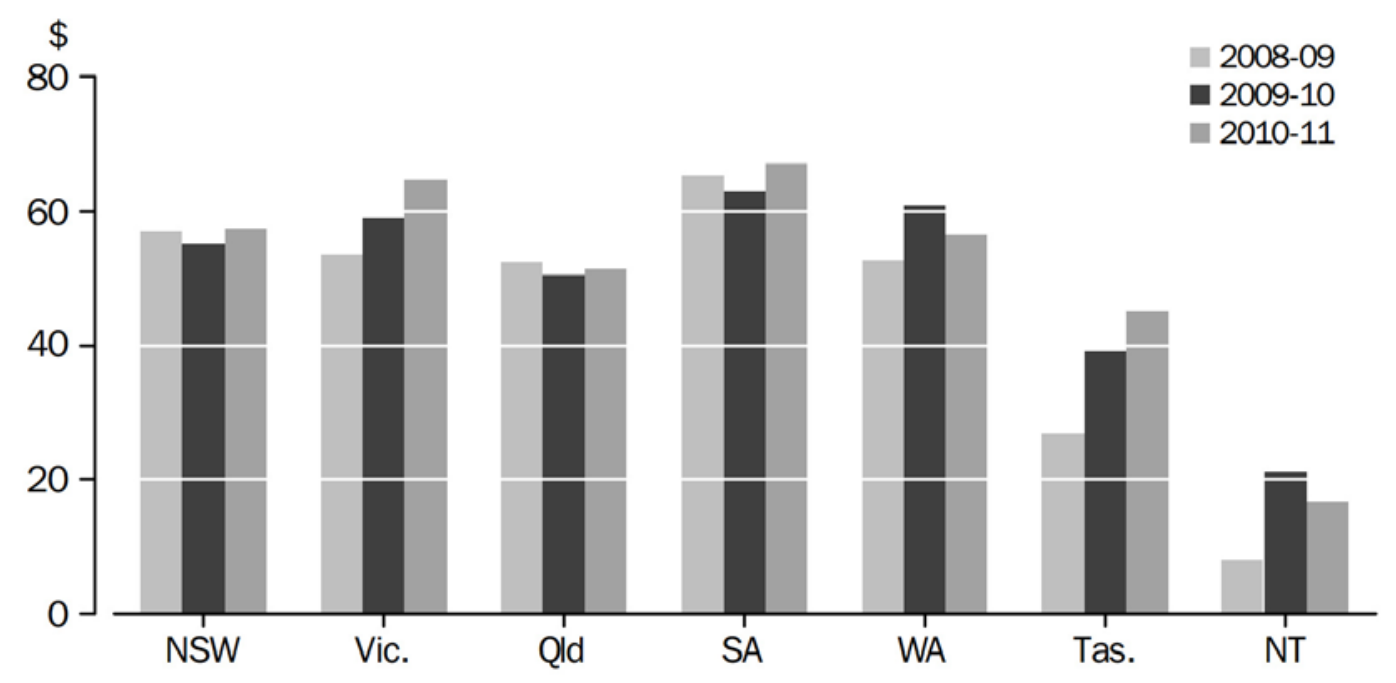

Fig. 1. Local government cultural expenditure per person by state and territory; 2008-09, 2009-10 and 2010-11 (ABS 2012, p. 35) 


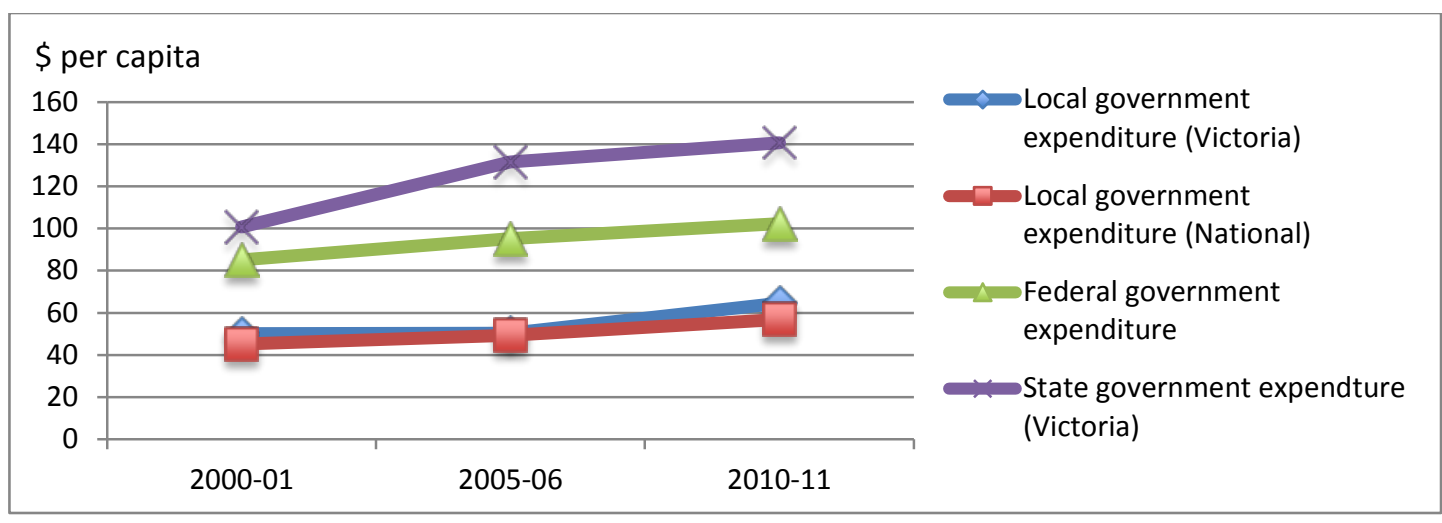

Fig. 2. Government expenditure on cultural activity per person 2000-2011 (ABS 2003; ABS 2007; ABS 2012)

\section{Size of the sector}

63 of the 79 Victorian councils have specialised cultural development staff. Mostly these were situated within a stand-alone Arts and Culture Department (10). 'Community Cultural Development' and 'Cultural Liveability' were two interesting versions of that title, implying a strong development focus. In other councils, cultural development staff were sited within departments that also had other responsibilities including community development (12), libraries (5), events (4), recreation (4), leisure (3), tourism (2), youth (2), economic development (1), access (1), venues (1) and learning (1). The 16 councils that did not have specialised staff mostly had some cultural development activity undertaken or overseen by staff from departments including community services/ development (12), economic and community development (2), economic development (1) and tourism (1).

\section{Staffing}

The number of council-employed staff in cultural development positions across the whole state was 342, with organisations employing between 20 (large regional town), 15 (outer suburban council) and one cultural development staff member. This does not include casual positions in venues such as performing arts centres and art galleries, of which there were an additional estimated 200 positions. Nor does it include library staff, which numbered between five and 95 per council, and 1,687 FTE across the state (Public Libraries Network Victoria 2012). While library staff and investment is included in figures quoted earlier re government investment in culture, the figures quoted in this section do not include library staff or resources, as they were not necessarily structurally connected with cultural development. This data is readily accessible from Public Libraries Network Victoria. 
Senior positions in arts and culture departments included roles as director (4), manager (38), co-ordinator (45) and team leader (19). Arts/community cultural development officer was the most common job designation, with 62 positions across the state. Regional councils were the least likely to have a cultural development officer position, with many bigger shires and regional towns only having staff connected to venues without a broader cultural development role, and the smallest shires having no staff. Festival/events officer roles were common (45), and 33 positions were dedicated to admin/PA responsibilities. More specific roles that only appeared in a few councils included marketing (6), public art (5), heritage (4), theatre director (4), media/publications (2), and arts access (1). Only five positions across the state included the word 'planner' or 'planning' in their titles.

Many positions were dedicated to venue management. These roles included cultural centre or community arts centre manager/co-ordinator (12), gallery manager (12) and performing arts centre/theatre manager (8). These were supported by a range of operational positions including curators/exhibition staff (27), technicians (11), and education officers (5).

The 13 LGAs that had no dedicated cultural development staff were all the smallest shires.

\section{Who has cultural plans?}

46 (out of 79 Victorian councils) had specific published cultural plans, and a further 10 had a plan in development. Almost half of these councils have had cultural plans prior to the current versions (23). These are commonly called 'arts and culture' 'plans' or 'strategies', although they primarily refer to the arts. City of Melbourne was the only council that did not include the word 'culture' in the title of its Arts Strategy.

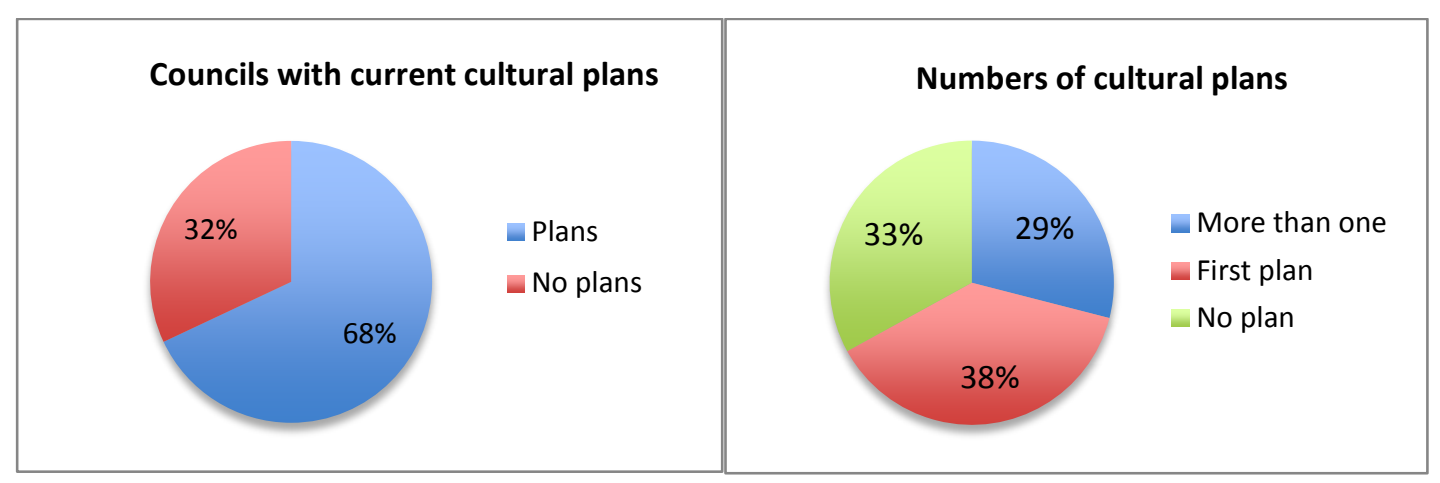

Figure 3. Distribution of cultural plans in Victorian LGAs 
A common pattern to the planning process was observed. The first plans councils made tended to be fairly basic and aimed at establishing council's engagement in this area. Second plans often included investment in infrastructure for cultural development. Third plans, in those councils that had revised their plans for the third time, focused on utilisation of facilities according to perceived community needs, but were also mediated by directives from council. In LGAs with more limited resources, plans included a priority on skill development for artists in the community and other potential arts participants rather than on infrastructure.

Most cultural plans were developed internally (35/53), some by a combination of staff and consultants (12/53) and a few (6/53) solely by external consultants.

Only three metropolitan councils did not have a published stand-alone cultural plan, although they all had published information about arts activities of their council. The majority of councils without specific plans were small-medium regional towns or shires. All but one of these mentioned some provision of arts and cultural services incorporated in other plans or strategies. These included six whose strategies were documented in regional strategic plans, such as the G21 Alliance in the Greater Geelong region, and the WimmeraSouthern Mallee Region Strategic Plan. Amongst LGAs that did not have a specific plan, cultural development policies were included in other strategic plans including tourism (7), council plans (4), health/wellbeing (4), economic development (2), and leisure and youth (1). Several of the councils that did not have a plan commented that it was not lack of interest, but lack of resources preventing a plan being developed.

\section{Community reference groups for cultural development}

Community reference groups for cultural development activities were common, with 56 of the 79 LGAs having some kind of advisory body. Forty councils with cultural plans had a community reference group, as did 16 councils that did not have a cultural plan. These groups were mostly general arts advisory committees (33), but groups were also focused on venues (8), heritage (7), local cultural development networking (6), multi-council activity (4), public art (4) and visual art collection (1). Two councils had specific committees to advise the development of the arts strategic plan.

\section{Policies or principles that inform the development of cultural plans}

To investigate policies and principles that inform cultural plans, published versions of these documents were examined. From this, it could be seen that the majority of cultural 
development strategies identify broader council plans as a guiding principle (28 of the 46 published documents). Hawkes' Fourth Pillar of Sustainability and Arts Victoria's Creative Capacity policy were mentioned by five councils. Ideas from UNESCO had some influence, with three councils mentioning UNESCO's Declaration of Human Rights, one council referring to UNESCO's 'City of Literature' initiative, and one using UNESCO's definition of culture. Other references or policies mentioned by one council each were: UCLG's Agenda 21 for Culture, the Federal Government's New Directions for the Arts, Arts Victoria's Strengthening Local Communities evaluation report, the State Government's Melbourne 2030 report, the Victorian Local Government Act, and Landry's Creative City. One council mentioned its own tourism plan as an influence. One council mentioned the Municipal Association of Victoria and one the Centre for International Economics as an organisation that informed their practice without providing any detail about specific policies or documents . In nine plans, no guiding principle was mentioned.

One frequent comment from council staff was that in developing new plans, they sought to create documents that were more strategic and better integrated with other council plans.

\section{Use of data, evidence and indicators.}

While there was much reporting of community consultation as part of planning cycles, the use of data to inform planning processes was not strongly evident, either to define issues to be addressed or consider their impact. Nor was there much cited use of evidence in decisions about actions to address specific goals. Most plans (44 out of 46) listed actions that had a relationship to stated goals. However, only 21 of the 46 plans listed any measurable indicators and targets.

\section{Discussion}

This comprehensive data gathering exercise about the cultural development sector in local government is the first to our knowledge in Victoria, and perhaps the first in Australia. With an investment of $20 \%$ of total government spending on culture, and employment of more than 550 staff in this sector across the state, local government's contribution is significant. This investment has grown more quickly than investment from State and Federal government. Such research therefore seems timely.

The first finding, gathered through desk-research and phone surveys, indicated that while departments referred to culture in their titles and plans, their work was almost exclusively 
concerned with the arts. This included heritage, but not the many other functions of councils that also have a relationship to culture, including diversity services and planning, education, indigenous issues and youth. These are almost exclusively organised in separate, although related, divisions.

Most councils had specialised cultural development staff situated within a stand-alone department, or in a department that identified arts or cultural development in its title. The number of staff was quite different, ranging from a team as big as 20 , to 13 councils that had no staff. Where departments had a function in addition to the arts, the most frequent alliance was with community development, followed by libraries. This pattern was also observed in councils, including all small regional shires that did not have specialised staff. In these LGAs, cultural development activities were most frequently supported by, or initiated within community service departments.

In terms of staffing, cultural development officer was the most common job designation, with 62 positions across the state across the majority of councils. Many councils also had senior positions dedicated to cultural development, including managers in almost $50 \%$ of councils and co-ordinators in more than 50\%. More than $50 \%$ of councils also had festival/events positions. Councils also had significant investment in venue staffing, with many positions dedicated to management and operations of venues, including cultural or community arts centres, galleries and performing arts centres.

Most councils had an 'arts and culture' plan or strategy in development (56/79), and many councils were developing a second and, in some cases, even a third iteration of this plan. These all referred to arts activities, rather than culture in a broader sense, although they also indicated attention to a range of broader cultural issues including diversity, creative expression, human rights, heritage, education and spirituality.

Alignment with the overall council plan was evident in the majority of cultural plans (60\%). However, this figure also indicates that $40 \%$ of cultural development plans did not have a significantly dynamic relationship with the overall direction of council to warrant it being mentioned in the plan. Few plans were informed by any other overall policy or principle. Influences quoted as guiding the development of cultural plans were disparate, with Hawkes' Fourth Pillar of Sustainability and Arts Victoria's Creative Capacity the most commonly mentioned documents, but only by five councils each. Given that Creative Capacity is a policy document developed by State government for its own operations, it might seem less than ideal as a guiding document for local government. Agenda 21 for Culture, the policy document for local government cultural development created by the 
international peak body for local government UCLG, was mentioned by only one council. This indicates significant scope for application of principles and policies relevant to cultural development in local government planning processes.

Not surprisingly, the smaller regional shires were the most challenged in terms of cultural development capacity. Lack of resources and specialised staff were major factors, compounded by lack of formal planning. However, not all smaller shires lacked plans. The reverse was also true, in that not all councils that invested significant resources in cultural development, such as dedicated staff and venues, had a plan. Several councils made significant investment in venues and related operations without any over-arching plan or staff with responsibility for broader cultural development activity outside the venues. These were mostly large regional towns, but also several metropolitan councils.

While current broader policy directives advocate the use of data in planning, evidence in decision-making, and evaluation of activities, these practices were not strongly evident in councils' published documents. Very few cultural development plans made any mention of data to inform their decision-making position or the use of evidence in development of strategies and actions. Measurement of outcomes was an area that indicated a lack of focus, with less than half of current plans listing indicators or measurable goals or targets. Lack of measurement strategies and targets mean that achievement of outcomes is much more difficult to determine. Theories of change were also missing in many plans, in that there was often no obvious logical relationship between goals, and activities intended to address those goals. These deficiencies were not confined to smaller councils, with as many larger metropolitan councils and regional towns lacking similar theories. These findings indicate significant potential for improved practice around goal setting and accountability.

What is evident, confirming Ley's (2012) recommendation for research relevant to local government, is the need for more data that can inform planning and decision-making, and increased application of this in practice. The lack of reference to relevant policy documents perhaps indicates both a dearth of relevant resources as well as a lack of awareness of those that exist. This points to the need for higher profile of relevant references such as UCLG's policy for cultural development. The prevalence of focus on councils' outputs, rather than outcomes for communities confirms Blomkamp’s (2012) observations of such practice even in progressive, well-resourced councils. This indicates a need for shifting of mindsets and heeding of maxims like that from Community Indicators' Victoria, discussed earlier, of the importance of focusing on outcomes for communities rather than the activities undertaken to achieve them. 
In the course of gathering this data, some needs became strongly evident. Overwhelmingly, council cultural development staff indicated a strong desire to have assistance with the development of their cultural plans. This was particularly evident for smaller regional shires, though not exclusive to them. Opportunities for knowledge sharing between councils was a frequent request, with colleague support and advice preferred to benchmarking or other comparative approaches that could be perceived as competitive.

\section{Areas for future investigation}

This article has addressed the investment of councils in cultural development activity, in resourcing, staffing, planning and community engagement. Many more issues not discussed in depth could offer further insight to councils. These include: whether theory of change principles are used in the planning processes; whether evaluation, including outcome measures are used; what these measures were; and what the relationship is of this to planning. More detailed examination of this data could provide correlations, for example, between the existence of a plan or community reference group and allocation of resources. A further process is recommended involving interviews with senior local government staff to determine their perceptions of the effectiveness of their current planning processes and the consequent challenges and opportunities.

This article has primarily focused, as local governments do, on delivery and support of cultural development activity. It has not addressed the major thrust of Hawkes' Fourth Pillar of Sustainability (2001) that the cultural dimension be integrated within all areas of council activity and reporting, along with social, economic and environmental concerns. As Hawkes' monograph has been influential internationally, for example, as the major platform of UCLG's Commission for Culture, this would be a worthwhile topic for future research. Two further areas of inquiry recommended by Markusen and Gadwa (2010) have yet to be examined: gauging the impact of cultural plans, and examining process and its influence on product.

\section{Conclusion}

This article has presented a picture of the current state of professional activity in the cultural development sector of local government in Victoria. In so doing, it offers the potential for accepted professional standards, improved collaboration and stronger shared practice and resources between councils. The survey undertaken for this project confirmed a 
significant investment of resources in cultural development in local government across Victoria, in staffing, venues, programming and support for local initiatives. However, the potential for improved practice in many areas of cultural development planning was evident. These include data-based planning, evidence-based decision-making, and use of outcome measures and targets. These issues need to be addressed if cultural development activity is to be most effective in supporting councils to achieve their goals of enhancing the quality of life for people in their communities.

\section{References}

Australian Bureau of Statistics (ABS) 2003, Cultural Funding by Government, Australia, 2001-02, cat. no. 4183.0, ABS, Canberra, viewed 13 September 2013, <http://www.abs.gov.au/AUSSTATS/abs@.nsf/allprimarymainfeatures/B727963BAF4D 8660CA256EDE00781BB1?opendocument>.

ABS 2007, Cultural Funding by Government, Australia, 2005-06, cat. no. 4183.0, ABS, Canberra, viewed 13 September 2013, <http://www.abs.gov.au/AUSSTATS/abs@.nsf/ allprimarymainfeatures/1494D4E6F8A09E89CA25749D0015247A?opendocument>.

ABS 2012, Cultural Funding by Government, Australia, 2010-11, cat. no. 4183.0, ABS,

Canberra, viewed 13 September 2013, <http:/www.abs.gov.au/AUSSTATS/abs@.nsf/ allprimarymainfeatures/4E552E1209B6711FCA257BB900114108?opendocument>.

Agenda 21 for Culture 2012, Adoption of Agenda 21 for Culture, United Cities and Local Governments, viewed 21 May 2013, <http://www.agenda21culture.net/index.php? option=com_content\&view=article\&id=45>.

Badham, M. 2009, 'Cultural Indicators: Tools for Community Engagement?', The International Journal of the Arts in Society, vol. 3, no. 5, pp. 67-75.

Blomkamp, E. 2011, 'Comparing the Uncertain Terrain of Local Cultural Governance in Australia and New Zealand', Australian Political Science Association Conference, Canberra, viewed 17 May 2013, <http://www.academia.edu/934681/Comparing_the_ Uncertain_Terrain_of_Local_Cultural_Governance_in_Australia_and_New_Zealand>.

Blomkamp, E. 2012, 'Control, Calculation and Collaboration in Cultural Policy Work at an Australian City Council', Asia Pacific Journal of Arts and Cultural Management, vol. 9, no. 1 , pp. 32-44.

Choudharey, R. 2009, Cultural Wellbeing and the Local Government Act 2002: A Hamilton Case Study, M Phil. Thesis, Auckland University of Technology, Auckland. 
Craik, J. 1997, Cultural policy case studies, Australian Key Centre for Cultural and Media Policy, Queensland.

Dalziel, P., Matunga, H. \& Saunders, C. 2006, 'Cultural well-being and local government: lessons from New Zealand', Australasian Journal of Regional Studies, vol. 12, no. 3, pp. 267-80.

Dunphy, K. 2006, 'Cultural development in Victoria, Australia; Policy and practice', Municipal World, September, pp. 21-2.

Dunphy, K. 2010, 'How can the impact of cultural development work in local government be measured? Towards more effective planning and evaluation strategies', Local-Global Journal, vol. 7, pp. 100-19.

Dunphy, K. 2012, 'Measuring the contribution of culture', Local Government Manager, vol. 45, no. 5, pp. 12-3.

Hawkes, J. 2001, The Fourth Pillar of Sustainability, Cultural Development Network Melbourne.

Ley, A., Baum, C. \& Lavarack, J. 2013, Knowledge City: The Difference an In-House Research Team Made to a Council and Its Community, Australian Centre of Excellence for Local Government, University of Technology, Sydney.

Local Government Act 1989 (Vic).

Markusen, A. \& Gadwa, A. 2010, 'Arts and Culture in Urban or Regional Planning: A Review and Research Agenda', Journal of Planning Education and Research, vol. 29, no. 3, pp. 379-91.

Meyrick, J. 2013, 'Does culture need explaining?', Encounters: Place/Situation/Context, the 17th Annual Conference of the Australasian Association of Writing Programs, Geelong, viewed 16 September 2013, <http://www.textjournal.com.au/april13/meyrick.htm>.

Mills, D. 2003, 'Cultural Planning: Policy Task, not Tool’, Artwork Magazine, no. 55, pp. 711.

Murray, C. 2005, 'Cultural Participation: A Fuzzy Cultural Policy Paradigm', in C. Andrew, M. Gattinger, M.S. Jeannotte \& W. Straw (eds), Accounting for Culture: Thinking Through Cultural Citizenship, University of Ottawa Press, Ottawa, pp. 32-54.

Public Libraries Network Victoria 2012, Annual Survey of Victorian Public Libraries 20112012, viewed 1 June 2013, <http://www.plvn.net.au/node/18>.

Smithies, J. 2012, 'The art of cultural development', Local Government Manager, vol. 45, no. 5, p. 11 . 
Stevenson, D. 2010, Cultural policy in Australia: institutions, audiences and communities,

On Line Opinion, viewed 4 July 2011, <http://www.onlineopinion.com.au/view.asp? article $=11260>$.

United Cities and Local Governments (UCLG) 2010, Culture: The Fourth Pillar of Sustainable Development, viewed 20 May 2013, <http://www.cities-localgovernments .org/upload/docs/docs_en_telechargements/C.129_ENG_Culture-is-the-fourth-pillar-ofsustainability.pdf $>$.

UNESCO 1982, Mexico City Declaration on Cultural Policies, viewed 16 September 2013, $<$ http://portal.unesco.org/culture/en/files/12762/11295421661mexico_en.pdf/mexico_en. pdf $>$.

West, S. \& Cox, D. 2009, A local government reporting framework for the 21st century: a response to the local government performance monitoring framework issues paper, Community Indicators Victoria, Melbourne. 


\section{Appendix}

\section{Research topics investigated through web search of published art or culture plans}

- Does council have an arts/cultural plan?

- What is the name of the cultural plan?

- Was this document developed in-house, by consultants, or a combination of the two?

- Is this the first plan, or were there previous versions?

- Is there a local cultural advisory group?

- Where are cultural services located within council?

- What other documents are noted as being relevant to cultural planning?

- Is there a noted relationship between the cultural plan and the broader council plan?

- What are the principles or policies that are named as guiding the development of the cultural plan?

- What areas and services are covered by the cultural plan?

- Does there appear to be a clear relationship between the cultural plan's goals and strategies for action?

- Is there any apparent use of data in establishing and evaluating the plan?

- Is there any apparent use of evidence from research or data in setting actions?

- Does the plan have measurable indicators and targets?

- What is the budget for cultural services?

\section{Questions asked in phone survey of cultural development staff}

- What is the job title (including department name) of all council staff in full-time or permanent part-time cultural development roles?

- At what stage is the arts or cultural plan: are there any developments beyond what is published on the website? 